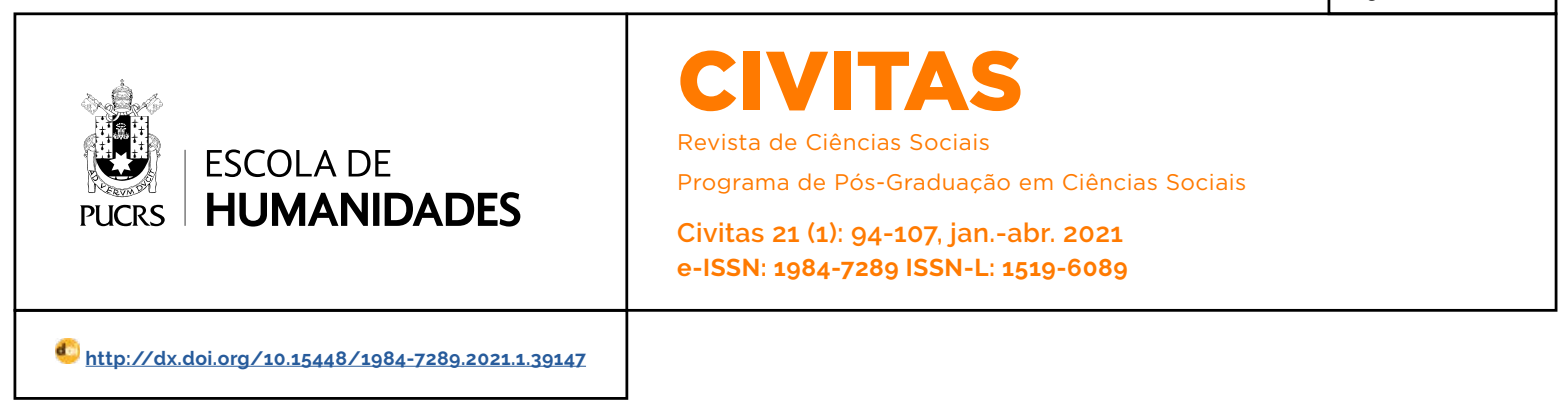

DOSSIÊ: TEORIA SOCIAL E SOCIOLOGIA EXISTENCIAL

\title{
Psicopolítica e mal-estar da contemporaneidade
}

\author{
Psychopolitics and contemporary discontents \\ Psicopolitica y malestar de la contemporaneidad
}

\author{
Alan Delazeri Mocellim ${ }^{1}$ \\ orcid.org/0000-0002-3929-4806 \\ a.mocellim@gmail.com
}

Recebido em: 14 set. 2020. Aprovado em: 5 nov. 2020. Publicado em: 7 maio. 2021.

\section{(c) (i)}

Artigo está licenciado sob forma de uma licença Creative Commons Atribuição 4.0 Internacional.
Resumo: Em O mal-estar da civilização Freud buscou apresentar uma discussão sobre os ganhos e as perdas da civilização, e em especifico sobre o mal-estar causado por suas limitações. Para Elias, a civilização, como prática, envolve o controle das condutas, a regulação dos modos e a subordinação das emoções. $O$ tormento trazido pela civilização decorre do modo pelo qual ela limita a liberdade, se sobrepondo aos impulsos, impondo tarefas culturais acima das vontades individuais. A civilização é a repressão social se tornando uma cobrança constante e internalizada como mal-estar. Nesse artigo busco articular sociologicamente, em contraposição a diversos autores da teoria social, o conjunto de hipóteses levantadas por Byung-Chul Han (2018b) sobre a psicopolítica, de modo a repensar os rumos e as transformações do mal-estar em uma sociedade não repressiva (fundada em negatividade), mas afirmativa (fundada em positividade).

Palavras-chave: Sociedade do cansaço. Psicopolítica. Mal-estar da civilização. Biopolítica. Capitalismo.

Abstract: In Civilization and its discontents Freud sought to present a discussion about the gains and losses of civilization, and specifically about the discontent caused by its limitations. For Elias, civilization, as a practice, involves the control of conduct, the regulation of modes and the subordination of emotions. The torment brought by civilization results from the way in which it limits freedom, overcoming impulses, imposing cultural tasks above individual wills. Civilization is social repression becoming a constant internalized demand as discontentment. In this article I seek to articulate sociologically, in opposition to several authors of social theory, the set of hypotheses raised by Han about psychopolitics, in order to rethink the directions and transformations of discontentment in a society that is not repressive (founded on negativity) but affirmative (founded on positivity). Keywords: Burnout society. Psychopolitics. Civilization and its discontents. Biopolitics. Capitalism.

Resumen: En El malestar de la civilización Freud buscó presentar una discusión sobre las ganancias y pérdidas de la civilización, y específicamente sobre el malestar causado por sus limitaciones. Para Elías, la civilización, como práctica, implica el control de la conducta, la regulación de los modos y la subordinación de las emociones. El tormento provocado por la civilización es el resultado de la forma en que limita la libertad, vence los impulsos, impone tareas culturales por encima de las voluntades individuales. La civilización es la represión social convirtiéndose en una demanda constante e internalizada como malestar. En este artículo busco articular sociológicamente, en oposición a varios autores de teoría social, el conjunto de hipótesis planteadas por Byung-Chul Han sobre la psicopolítica, con el fin de repensar las direcciones y transformaciones del malestar en una sociedad no represiva (fundada en la negatividad), pero afirmativo (basado en la positividad).

Palabras clave: Sociedad del cansancio. Psicopolitica. Malestar de la civilización. Biopolítica. Capitalismo. 


\section{Repressão e mal-estar da civilização}

Em O mal-estar da civilização Freud (2011) busca articular psicanálise e análise da cultura; trata-se de um texto tardio dentre outros textos em que Freud buscava refletir sobre a civilização europeia e a modernidade. Em específico, 0 principal tema que o inquietava eram os "ganhos e perdas" da civilização, ou seja, do que abrimos mão para termos uma cultura racional, o que temos como penalizações por viver em uma sociedade fundada em um estrito ordenamento, e em que medida a civilização pode significar possibilidade ou limitação. O texto é iniciado com uma reflexão sobre a relação entre o Eu e o mundo, sobre o Eu no mundo, para seguir para uma reflexão sobre o "sentimento oceânico" supostamente ligado à experiência religiosa. A religião é discutida por Freud em várias dimensões, sendo pensada, sobretudo, em sua relação com a felicidade e o sofrimento, como modo de realização e como modo de limitação. O foco, no entanto, não é a religião em si mesma, mas a questão da possibilidade de uma felicidade consistente e duradoura, e a religião é apresentada como uma promessa dessa felicidade que não pode, por meio dela, se realizar. No entanto, não é só a religião uma promessa não cumprida, mas também a civilização. Ela também nos oferece soluções, caminhos, um destino a ser alcançado no futuro se negarmos nossas vontades hoje, se a abraçarmos com todas suas repressões. $O$ trágico, em Freud, é que também a civilização não se realiza enquanto promessa de felicidade.

Para pensar a felicidade Freud reflete sobre três fontes possiveis de sofrimento: a prepotência da natureza, a fragilidade de nosso corpo e a insuficiência das normas que regulam os vínculos humanos (Freud 2011, 30). Todas essas três fontes, em conjunto, levam a uma conclusão trágica: a felicidade plena é impossivel, pois seremos sempre, em alguma medida, coagidos e limitados por tudo isso que compõe nosso mundo - a natureza exterior, nosso corpo, as relações humanas - pois se trata de forças contingentes, que vão além das vontades individuais. Dessas três fontes de sofrimento, Freud centra sua dis- cussão na terceira, na relativa às relações sociais, que em sua época pôde ser descrita a partir do termo civilização. Freud discute a postura de hostilidade à civilização em sua época - presente, por exemplo, tanto na literatura romântica como nos nacionalismos - como uma amostra de que a civilização não traz só vantagens, mas traz limitações que são sentidas como perdas, como problemas, como coações. De um lado, a civilização, a partir da repressão cultural de impulsos, permitiu um direcionamento deles para a produção cultural, para o ordenamento social, para a arte, para a ciência e para a política; de outro lado, a civilização, nos protegendo na natureza e de nós mesmos, criando esse mundo ordenado, nos subjuga a esse mundo e às regras cada vez mais restritas da vida cultural.

E onde encontramos essa civilização? O que nela nos atormenta? A civilização, como conduta civilizada, pode ser identificada com um conjunto de modos de ser que se disseminaram pela Europa, desde o século 17, compreendendo a valorização do controle das emoções, do biológico, a prática das boas maneiras, o cultivo da arte e da ciência (Elias 1993). A civilização é definida pela ordem, pela limpeza, pela racionalidade. A civilização, como prática, envolve o controle das condutas, a regulação dos modos, a subordinação das emoções. O tormento trazido pela civilização decorre do modo pelo qual ela limita a liberdade, se sobrepondo aos impulsos, impondo tarefas culturais acima das vontades individuais. Ganha-se com a civilização uma menor violência física cotidiana e um maior ordenamento da vida social que nos permite empreender atividades produtivas, mas perdemos com a civilização parte de nossa experiência emocional, que se encontra sempre subordinada a expectativas sociais, cada vez mais vivenciadas também dentro de nós. A civilização está fora, mas está dentro, é a repressão social se tornando uma cobrança constante e internalizada.

Em "Totem e Tabu" (Freud 2012), ao buscar refletir sobre as sociedades "não civilizadas", Freud conclui que é sobre o "não" que se constroem as sociedades. A organização da sociedade é 
descrita, em seu estudo, em torno da proibição do incesto, da limitação sexual como forma de estruturação da cultura, mas os tabus, vividos pelos polinésios como algo mágico, continuam presentes destituidos de magia, de forma que a proibição do incesto é a mais antiga e a mais atual, por isso a mais permanente das regras sociais, tendo uma força estruturante da própria vida cultural (Lévi-Strauss 1982). Da mesma forma que evitamos a violência e a agressividade, a expressão emocional intensa e a sexualidade, é parte da civilização evitar a morte, até mesmo evitar falar da morte. Na modernidade a morte é segregada, separada do mundo, transformada em experiência extracotidiana com a qual o contato deve ser evitado (Elias 2001b). A civilização é, para essa experiência, também negação; as religiões modernas reproduzem o mesmo, negando a morte como definitiva, oferecendo conforto diante dessa experiência destruidora e definitiva (Freud 2010b). Novamente, aparece aqui a sociedade se construindo em torno de proibições que atuam, por meio da norma, formando o autocontrole, traço de uma sociedade internalizada, como nos lembra Elias (1993), psicologizada em antecipação dos outros e de suas expectativas, ou, dito à maneira de Mead (2010), um self formado a partir do outro generalizado que é a sociedade, e que por isso, partindo das atitudes sociais regulares formamos nossa atitude autônoma, sendo nossa mente autoconsciente um refletir sobre os outros, os antecipando, e assim refletindo sobre si mesmos.

Quando falamos de civilização e tabus falamos de proibições; se hoje temos outros totens, permanecem, no entanto, as coerções, talvez não descritas como proibições, mas mesmo assim com seu caráter de dever. Se em torno das proibições construímos neuroses e obsessões, o que será que podemos construir quando as nossas formas de coerção não são mais percebidas como proibições, mas como liberdade? Para responder essa questão pretendemos apresentar e articular algumas reflexões do filósofo e ensaísta cultural Byung-Chul Han (2017b, 2018b), com as contribuições da teoria sociológica para repensar o mal-estar, não mais como um mal-estar da civilização, com suas repressões baseadas em proibições, mas como um novo mal-estar, caracteristico de uma sociedade de alta-modernidade, hipermodernidade, de uma sociedade da informação.

A hipótese central de Freud (2011) em seu $O$ mal-estar da civilização era de que toda sociedade, por meio de suas proibições, produz um tipo especíico de sujeito, com seus problemas específicos, relativos sempre às repressões e às coerções enfrentadas. Elias (1993), em sua discussão sobre o processo civilizador, de maneira similar, diz que a psicologização e a racionalização do outro, junto da incorporação das regras de conduta social como códigos internalizados, que nos impulsiona a uma autorrepressão, não é algo universal de todas as sociedades, mas resultado de um modelo de sociedade, de uma organização social que, tal como em uma sociedade de corte (Elias 2001a), com suas regras muito particulares de atribuição de valor social por meio da contenção emocional, se estrutura e atribui valor social à supressão de instintos, impulsos e vontades, em nome de uma etiqueta social repressiva, vivenciada por isso como autocontrole. Han (2017b, 2018b), com suas discussões sobre a sociedade de cansaço e o nascimento da psicopolítica, busca, em diálogo com Freud (2011) e Foucault (2008, 2014), questionar os rumos e as transformações de nosso mal-estar em uma sociedade não repressiva (fundada em negatividade), mas afirmativa (fundada em positividade). Nesse artigo pretendemos articular sociologicamente o conjunto de hipóteses levantadas por Han (2017b, 2018b) para repensar o mal-estar na contemporaneidade.

\section{Sociedade disciplinar e sociedade do desempenho}

A partir de Foucault (1979), compreendemos uma sociedade disciplinar como uma sociedade repressiva, mas também produtiva. A organização da sociedade disciplinar limita, regula e direciona o poder, mas esse poder também é produtivo, permite fazer, direciona e incrementa a produção. Essa sociedade disciplinar, que reprime e produz, é também o modelo de sociedade civilizada. Como nos mostrou Weber (2006), em seu estudo 
sobre as relações entre protestantismo e capitalismo, disciplina e capitalismo são práticas sociais que se alimentaram reciprocamente ao longo da história moderna. O protestante, descrito por Weber (2006) como tipo ideal, angustiado com o medo da condenação e a busca da salvação, se disciplinava no trabalho; sua disciplina no trabatho se tornou, com o passar do tempo, a própria disciplina da vida capitalista. A vida monástica dos monges, a vida austera dos protestantes e a vida disciplinada dos capitalistas modernos se aproximam na medida em que, por meio da regularidade imposta, e rotinizada, buscavam amplificar os produtos de seu trabalho. $O$ ideal protestante de disciplina para o trabalho, com sua consequente rotinização da vida, foi, nesse sentido, componente essencial para o desenvolvimento do capitalismo moderno (Pierucci 1998).

Para Foucault (1979), o poder disciplinar se segue ao poder do soberano. A soberania é aquela forma de poder sobre o território, a vida e a morte. O poder soberano é o poder organizado em torno da possibilidade de o monarca impor sua vontade em nome de um pacto social, a violência é seu modo de ação primordial. A soberania é, assim, caracteristica do poder feudal e perdurou até o século 17. O poder disciplinar, em oposição, é o poder tipicamente moderno. Em ascensão e expansão desde o século 18, a disciplina incide sobre os corpos, por meio de coerções e regulações, articuladas por meio do direito e da medicina. O poder disciplinar é o poder da vigilância constante, das regras estritas e bem definidas, da lei e da ordem. O modelo mais representativo do poder disciplinar é o panóptico. Enquanto arquitetura de controle, com um panóptico tem um centro de onde se permite a observação do todo, seu objetivo é permitir a rotinização do controle. Por meio da visibilidade se induz ao funcionamento automático do poder, que se torna coletivo e sistêmico, atuante por meio de agentes, e promovendo efeitos homogêneos de padronização de condutas e de amplificação de eficiência (Foucault 2014). A subordinação do corpo e a automatização das condutas para o bom desempenho de práticas esperadas é o resultado do poder disciplinar.

A sociedade disciplinar se funda na restrição, no estreitamento das relações, nos códigos claros de conduta correta, e, sobretudo no confinamento. A fábrica, com sua ordem na linha de produção, é o modelo (e talvez o maior de todos, porque caracteriza o capitalismo industrial) de uma sociedade disciplinar, ou dito de outra forma, a linha de produção, com sua produção em cadeia com etapas definidas, espacialmente e temporalmente delimitada e supervisionada, é o modelo de engenharia social do capitalismo pesado (Bauman 2001), de maneira que é estendido para outras formas de organização, como os presídios, nos quais a organização especial e temporal é reproduzida com os mesmos propósitos disciplinares direcionados a integração no capitalismo (Melossi e Pavarini 2006). O modelo disciplinar vai muito além da repressão ou da produção, ele promove também aquilo que Giddens (2002) chamou de segregação da experiência, ou seja, processos que removem do cotidiano aquelas experiências que rompem com a continuidade funcional $e$ evocam dilemas morais, como a loucura, a criminalidade, a doença, a morte, a sexualidade, e o caráter imprevisivel da natureza. Uma sociedade disciplinar mantém a segurança ontológica pela remoção das experiências que abalam a crença na continuidade e na regularidade.

A sociedade disciplinar é, sobretudo, fechada, limitadora, e se organiza em torno do corpo que trabalha e age, produzindo. Tal quadro se modifica em uma sociedade do desempenho, que se apresenta como aberta às oportunidades, livre, e que se organiza pelo raciocínio, iniciativa e motivação, atributos atribuídos ao psicológico, enquanto núcleo de pensamento e de emoção. O poder disciplinar atua no corpo, pois "a técnica ortopédica do poder disciplinar é muito grosseira para penetrar nas camadas mais profundas da psique" (Han 2018b, 35). Mas é justamente da psique que uma sociedade do desempenho se ocupa; ela visa à otimização mental para otimizar a produção material. Essa sociedade do desempenho é resultado direto do neoliberalismo, e seu sujeito representa um agravamento dos aspectos 
do homo oeconomicus. Se em sua concepção clássica, liberal, o homo oeconomicus era aquele envolvido na troca de mercadorias, na negociação, em sua versão neoliberal é um empresário de si mesmo, sendo ele mesmo o seu capital (Foucault 2008, 311). A antropologia filosófica do neoliberalismo, sua concepção de ser humano, apresenta o homo oeconomicus como modelo geral da conduta humana, finalista, calculista, orientada por estratégias e totalmente racional. É do homo oeconomicus neoliberal, como descrito por Foucault, que emerge o ideal de sujeito de uma sociedade do desempenho.

Ao contrário do sujeito de uma sociedade disciplinar, explorado por capitalistas e sujeito ao estado, o sujeito de uma sociedade de desempenho se autoexplora com a convicção de que o faz livremente, de que não é servo de ninguém, de que apenas busca seus objetivos e realiza seus projetos (Han 2018b). É não apenas um empreendedor individual, mas um empreendedor de si, que calcula suas ações de maneira finalista, que se cobra ao desempenho, e que acredita que não há nada de "social" o impulsionando a tal atitude, exceto a sua própria vontade. Cabe-nos, então, perguntar: quem impulsiona a busca por desempenho e a autoexploração em uma sociedade do desempenho? Diferente de uma sociedade disciplinar, onde há uma coerção advinda de um polo emissor, embora todos tenham que se submeter a essa coerção, mesmo os emissores, em uma sociedade do desempenho todos produzem a regra e a coerção por si mesmo, e reproduzem em discurso. Ser ativo, fazer, repetir e continuar são imperativos de época, formam um "espírito do tempo", impulsionados, sobretudo, pelo capitalismo da informação, que por meio do big data extrai nosso "psicograma coletivo" (Han 2018b. 36) e incentiva tecnologias do eu (Han 2018b, 43) que otimizam desempenho.

Uma sociedade do desempenho não deixa de ser violenta, e aí reside um de seus mal-estares. Embora sua violência sistêmica não seja física e direta, ela é uma violência indireta, internalizada. A cobrança pelo trabalho, pelo sucesso, pela liberdade, pelas vivências transitórias leva ao cansaço e ao esgotamento, e esse esgotamento é uma autoagressão (Han 2017b). Trata-se também de uma violência do consenso, porque se todos estão em competição, em busca de afirmarem como livres, não se é permitido escolher não estar. O resultado dessa violência neuronal são as psicopatologias contemporâneas, como a depressão e o burnout. Tal como a neurose era a psicopatologia representativa do mal-estar moderno, as psicopatologias da atividade (deficit de atenção e hiperatividade) e esgotamento (depressão e burnout) são representativas de um novo mal-estar, produzido por uma sociedade que não mais proíbe e recalca, mas que impulsiona ao fazer cada vez mais. Elas se somam às psicopatologias do autocentramento (narcisismo) e da instabilidade emocional (borderline) como respostas às demandas dessa nova sociedade.

\begin{abstract}
É inerente à sociedade pré-moderna da soberania a violência da decapitação; seu medium é o sangue. A sociedade disciplinar moderna é. em grande medida, uma sociedade da negatividade, sendo regida e dominada pela coerção disciplinar, isto é, pela 'ortopedia social'. Sua forma de violência é a deformação. Mas nem a decapitação e nem a deformação estão em condições de descrever a sociedade de desempenho pós-moderna. Ela é dominada por uma violência da positividade, que confunde liberdade e coerção. Sua manifestação patológica é a depressão (Han 2018b, 183-184).
\end{abstract}

De um modo geral, os transtornos depressivos abarcam um grande conjunto de sintomas afetivos, cognitivos e comportamentais possiveis, tais como humor deprimido, desânimo e perda de interesse, alterações no apetite e no sono, anedonia, fadiga e perda de energia, pessimismo, baixa autoestima e autoconfiança, concentração prejudicada, pensamentos de morte e suicídio, passividade ou agitação (Dalgalarrondo 2008). A esse conjunto básico de sintomas, juntam-se outros que, conforme incidência permitem classificar os tipos e subtipos de depressão. Sua amplitude, como conceito, é tal, que sua definição se torna complexa, e se liga, sobretudo, à inatividade, à passividade, ao pessimismo e à inação. Tal como Han (2018b), Ehrenberg (2004) liga a depressão ao capitalismo contemporâneo a caracterizando, sociologicamente, como resultado de 
[...] uma transformação de grande amplitude da normatividade social: a passagem de uma sociedade que se refere à disciplina (interdição, obediência, autoridade, etc.) para uma sociedade que se encontra sob o primado da autonomia (Ehrenberg 2004, 147).

É dessa forma que a passagem da sociedade disciplinar para a sociedade do desempenho se refere à inversão do eixo das repressões (negatividade) para as permissões (positividade), da negação das possibilidades para a afirmação de possibilidades. Segundo Han (2017b), o século 20 representou uma aprendizagem social dos limites da disciplina, com a constatação de que, em certo ponto do capitalismo, proibir e bloquear não poderiam resultar em incremento do crescimento econômico. A sociedade do desempenho, com sua psicopolítica, representaria o ponto de encontro do neoliberalismo com uma nova práxis social: a positividade do poder como garantia do crescimento e da impossibilidade de estagnação. Equalizando liberdade com produtividade e responsabilidades individuais por seu sucesso e fracasso, o capitalismo não teria, a partir daí, limites em suas possibilidades de ampliação.

\section{Biopolítica e psicopolítica}

Com as reflexões de Arendt (2007) tivemos o alerta de que a transformação da política em administração, em gerência da produção, representava algo distintivo para a era moderna. Foucault (1999) leva esse alerta adiante no conceito de biopoder, com o qual busca sintetizar a forma como a organização política moderna, sobretudo centrada no Estado, mas também por meio do capitalismo, gerencia os corpos, e tem como objetivo central a gestão da vida e da organização da população. A biopolítica é, assim, uma forma de poder centrada na gestão da população, visando sua manutenção, seu crescimento, sua saúde e sua vida. Estatística, medicina, direito e logística são agrupadas para essa gestão, que é sobretudo uma gestão econômica das sociedades, visando sua racionalização e bom desempenho.

Em oposição, para Han, vivemos não mais uma época de biopoder, mas vislumbramos a ascen- são do psicopoder. Essa nova forma de poder, fruto de um capitalismo da informação, atua por caminhos muito mais eficientes, e inteligentes, que o biopoder, pois

\begin{abstract}
o poder não se limita a quebrar a resistência e compelir à obediência: não tem que necessariamente assumir a forma de coerção. [...] o poder está precisamente aonde não é posto em evidência. Quanto maior é o poder, mais silenciosamente atua (Han 2018b, 25).
\end{abstract}

Se o biopoder é negativo, composto por negações, proibições, regras de conduta correta, ordenada e saudável; o psicopoder é positivo, ele permite, autoriza a ação, desestimula as restrições. Ao invés de oprimir, se busca libertar e motivar; ao invés de punir os erros e excessos, se busca manter a sensação de gratificação para impulsionar a dependência. Enquanto o biopoder funciona pelas emoções negativas, pelo medo da punição, pelo medo da morte, o psicopoder funciona pelas emoções positivas, pela euforia, pela participação, pela congregação. O problema é que um poder negativo é limitado a espaços aonde essa relação de sujeição é possivel, mas o um poder positivo, por se fundar no ganho e não na perda, pode ser ampliado ao infinito, para todos os âmbitos da vida.

O psicopolítica não tem polo emissor, não tem locus, trata-se de um novo pacto social, de um imperativo coletivo para o fazer. Isso não significa que não há produtores de psicopoder, pois a psicopolítica é também um modo de organização societária, com seus representantes. A organização informacional do Estado, o neoliberalismo orientado pela amplificação exponencial de informações, tudo isso contribui para a produção de informação, e daí para uso da informação para a manutenção do impulso a ela mesma. O estímulo à circulação e à continuidade da comunicação é o instrumento psicopolítico por excelência. A livre informação, sem restrições, coloca todos em ação, como uma multidão de indivíduos atomizados. A vigilância digital que atua sob autorização e desejo de todos aqueles que usam redes sociais serve para esse impulsionamento constante, aonde por meio de um 
espírito de liberdade e de livre expressão, se dá a reprodução e a continuidade de um modelo, que é o da coação de si mesmo ao fazer e ao produzir, seja produzir bens, seja produzir informação (Han 2018a). O panóptico digital não limita, mas impulsiona, e impulsionando ele vigia e influencia o comportamento a partir da coleta de dados.

Para Arendt (2007), a sociedade moderna, como sociedade do trabalho e do fazer, se sobrepõe a uma sociedade fundada no agir, enquanto decidir e realizar politicamente, e por reduz o ser humano a um animal laborans, ao fazer pela sua mera sobrevivência. A vita activa moderna, reduzida ao trabalho, não só solapa a ação, como solapa também a contemplação - não temos mais tempo para refletir, apenas para fazer. Nosso pensar agora é cálculo, racionalidade com relação a fins, orientação econômica. O animal laborans atual transforma o fazer em seu mantra, não só fazendo porque há uma demanda social pela produção ou porque o trabalho engrandece, mas busca fazer porque não vê alternativa, e equaliza fazer e liberdade. Han (2017b) complementa que não se trata só da busca por coisas, mas também pela busca de vivência, do completamente novo, de um novo estímulo ou de uma nova aprovação.

Psicopolitica também remete, para Han (2018b), à aceleração social, mas de um modo contraditório. Tal como Elias (1998), Han (2018b) argumenta que a aceleração do tempo é constitutiva da modernidade, que a passagem do tempo abandona os rituais que o encadeiam em eventos, se tornando, com a desritualização da passagem do tempo, uma aceleração acumulativa, mas improdutiva. Argumentando de maneira similar a Rosa (2019), que destaca que a aceleração social, fruto da divisão do trabalho, da racionalização e do capitalismo, além de acelerar processos cria também seu inverso, a paralisação e o congestionamento, como efeitos colaterais, Han (2018b) afirma que o impulso para aceleração de produtividade. atribuido aos indivíduos, gera seu inverso, como "infarto do sistema" e colapso individual. A aceleração significaria, desse modo, não apenas um aumento de racionalização, um aprofundamento de individualização na divisão do trabalho, mas também um aumento de entropia, uma saturação de atividade, produção e comunicação.

Estar ativo, e hiperativo, é parte de um código moral de uma sociedade psicopolítica, no qual autoexploração é liberdade. Temos assim, com a psicopolítica a demolição do código de proibição civilizacional, do ordenamento típico da disciplina e da biopolítica, em nome de um ordenamento que coloca no eu a responsabilidade e o imperativo de ação (Han 2018a). A psicopolítica traz um novo mal-estar, com o fazer se tornando seu dever, com a coação ao poder tudo, deixando de lado os limites da disciplina em nome da potência da liberdade. Ela impulsiona a concorrência individual internalizada, um impulso de autossuperação, que se não realizada se transforma em culpa e sensação de fracasso (Han 2018b). A psicopolítica internaliza a lógica concorrencial do capitalismo, dessa vez não como outros a serem enfrentados no mercado, mas contra si mesmo. Com a obrigatoriedade de tudo fazer, com a disputa contra si em um capitalismo internalizado como liberdade, o cansaço é inevitável.

\section{Capitalismo, transparência e cansaço}

O capitalismo de uma sociedade do desempenho tem como imperativos o fazer sempre e mais, e o mostrar sempre e mais. É nas coações do fazer e do mostrar que desempenho e transparência levam ao cansaço. Além do fazer, com a necessidade de transparência, somos impulsionados a mostrar, a participar e a exibir o eu que faz. No ethos da transparência, o sucesso está na proximidade, e não no distanciamento, e por isso há a necessidade de uma comunicação constante, que retroage em acúmulo e excesso de informação (Han 2017a). Psicopolítica e big data se inter-relacionam no capitalismo. O big data funciona como instrumento psicopolítico para otimização da produtividade. Agindo nas redes sociais, sendo um "cidadão digital" se concede informação livremente, com essa informação produtos e serviços são melhor direcionados, o empreendedor de si, para ser parte de um mundo de consumo produz para comprar, e ao mesmo tempo tem direcionada a si, pelos meios de comunicação, um conjunto 
de ideias e valores que reforçam seu caráter livre e não sujeito, sua visão de si como sujeito não determinado, agindo conforme suas próprias vontades, escolhendo e trabalhando do modo que optou. Seu objetivo é o consumo, autorrealização e autoafirmação (Han 2018b).

A pessoa se torna coisa que produz coisas, mesmo que seja informação ou experiências, algo não muito diferente do trabalhador descrito por Marx (2004), que se encontra preso no ciclo de produção, sem conferir sentido ao seu trabalho desprovido de sua conexão mais profunda com o que faz. A diferença, no entanto, é que o trabalhador explorado pelo capital industrial se percebia como explorado, enquanto o trabalhador do novo capitalismo se vê como livre, fazendo escolhas e dispondo de opções. 0 trabalhador de um capitalismo industrial, ao estar desempregado entende que as causas de seu sofrimento são partes da produção e de escolhas de outro, mas o trabalhador do novo capitalismo se vê como fracassado, como alguém que não fez o suficiente. A transformação do trabalhador em um empreendedor, alguém que se orienta não mais pelo trabalho em um lugar, mas em projetos individuais e metas, é núcleo central de um novo conjunto de ideias sobre o trabalho, de um novo espírito do capitalismo (Bolstanski e Chiapello 2009), que acompanha as mudanças de um capitalismo industrial para um capitalismo financeiro - o que Han (2018b) vê, por sua vez, como intrínseco ao capitalismo do imaterial

O neoliberalismo, como mutação do capitalismo, torna o trabalhador um empreendedor. [...] Na produção imaterial, de um jeito ou de outro, cada um possui o seu meio de produção. $O$ sistema neoliberal não é mais um sistema de classes em sentido estrito. Ele não se constitui por estratos antagônicos da sociedade. E é aí que reside a estabilidade do sistema. [...] é disseminada a ilusão de que qualquer um, enquanto projeto que se esboça livremente, é capaz de autoprodução ilimitada (Han 2018b, 14-15).

Para Boltanski e Chiapello (2009), o espírito do capitalismo é um conjunto de crenças que serve de justificativa para uma ordem social e legitima ações dentro dessa ordem, garantindo assim uma existência em harmonia com a acumulação. O espírito do capitalismo compreende as visões de mundo sobre o capitalismo, com justificações individuais e coletivas para sua forma econômica. Os pilares do espírito do capitalismo foram formados pelas crenças em seu progresso material, sua eficiência na satisfação de necessidades e como modo de organização livre. Para os autores, cada época, cada transformação do capitalismo, traz consigo um novo espírito, enquanto conjunto de crenças. Se o espírito do capitalismo descrito por Weber (2006) tratava de uma ordem social burguesa emergente, ainda tradicional, mas com grande nivel de inovação técnica no trabalho, e se outros espíritos o sucederam com o capitalismo globalizado, para Boltanski e Chiapello (2009), o novo espírito do capitalismo é aquele do discurso empresarial da década de 1990, que se apresenta como ideologia dominante acerca das representações sobre a economia. Esse novo espírito é caracterizado por valores relacionados à mudança, à diminuição, ao desenvolvimento de projetos individuais e descentralizados, à mobilização espontânea, à flexibilidade no trabalho e à autonomia. O foco desse novo discurso a respeito do capitalismo, apresentado como ideologia dominante, é a autonomia do trabalhador, liberto das obrigações empresariais rígidas. O trabalhador agora é empreendedor de si mesmo, e os manuais de autoajuda são seus guias espirituais nessa empreitada.

De forma análoga, Ehrenberg (2010) vê no culto da performance, trazido do esporte e da aventura, carregado de chavões empresariais, como um discurso ideológico sobre a positividade da disputa, do empreendimento, da busca de resultados, das vitórias a todo custo. O indivíduo performa como um atleta em busca de otimização econômica; deve ser bravo e vitorioso, enfrentando todos os desafios. Mais do que uma opção, se otimizar para a performance, para a obtenção de sucesso, se torna uma norma social, e como norma, exige sacrifícios. A medicalização da vida, para otimizar o empreendedor de si já cansado, se torna uma opção. A competição não pode parar, e os riscos devem sempre ser assumidos. As 
emoções devem ser positivas ou ignoradas nessa busca. Ou dito ao modo de Bauman (2001), na passagem de uma sociedade de produtores para uma sociedade de consumidores, do capitalismo industrial (sólido) ao capitalismo da informação (líquido), o inconformismo e a adaptação se tornam virtudes, ser maleável e estar em movimento são obrigações, o indivíduo deve enfrentar suas frustrações sempre, sozinho e individualizado.

O capitalismo da informação, do que nos fala Han (2018b), é também um capitalismo emocional, mas de emoções muito bem definidas. Diferente de um capitalismo industrial e de sua óbvia exploração do trabalho ou do capitalismo dos protestantes que viam no sofrimento uma fonte de virtude, o capitalismo da informação se vale das emoções positivas e reproduz um discurso sobre a liberdade e a euforia. Emoções negativas são desestimuladas e, por isso, o excesso de positividade. Vive-se na positividade da busca de gratificação, que eventualmente esgota o sujeito em seu excesso de atividade. Han (2018b, 59-68) distingue sentimentos e emoções, atribuindo ao sentimento uma continuidade temporal e às emoções a vivência situação no agora, no presente imediatamente vivido. O capitalismo industrial podia ser sentimental, porque era contínuo, impunha um ritmo de vida fundado na rotina, mas só o capitalismo informacional pode ser emocional, porque exige a todo o momento novos empreendimentos, uma nova doação de si, de um eu que busca a emoção em um momento para não lidar com ela extinta no momento seguinte. Essa dualidade muito se assemelha à diferença que Bauman (2001) faz entre os modos de individualização no capitalismo sólido e no capitalismo líquido, sendo o primeiro modo fundado na busca de ser individuo situado em uma comunidade, e o segundo construção estética da identidade, por meio de experiências transitórias de consumo.

Illouz (2011) atribui esse aspecto emocional do capitalismo a uma série de mudanças nas sociedades contemporâneas. De um lado, com a entrada da linguagem da psicologia na empresa capitalista, com suas práticas motivacionais, e com a difusão da autoajuda e literatura focada no bem-estar, aquele elemento sistêmico, mais racionalista, de nosso cotidiano no trabalho se torna emocional; as emoções passam a ser reconhecidas no discurso público, como justificativas suficientes, como modos de se comunicar. De outro lado, em contradição, o campo afetivo por excelência, aquele da vivência familiar e dos relacionamentos intimos, se racionaliza com relação a fins, se torna pragmático, mais "capitalizado". Para Illouz o capitalismo emocional tem essa dupla linguagem, do mundo público do racional emocionalizado e do mundo íntimo racionalizado, com os afetos ali sendo geridos como bens e mercadorias. Han (2018b), em oposição, vai dizer que a transformação do público em emocional faz parte desse capitalismo da informação, que torna até mesmo o intimo transparente, algo exposto e destinado ao consumo, e ao mesmo tempo emocional, porque é constitutivo da psicopolítica a busca de envolvimento emocional em todas as práticas.

Como toda experiência negativa deve ser evitada, o sofrimento do fracasso na sociedade de desempenho é análogo ao inferno do protestante descrito por Weber (2006), que disciplinado e trabalhando, ao não ser produtivo, se vê condenado. Giddens (2002) compara a angústia dos protestantes capitalistas na busca pela salvação, disciplinados para o trabalho para evitar a condenação, às pressões civilizatórias descritas por Freud (2011); tanto a disciplina para trabalhar, como a repressão dos impulsos, caso transgredidas, levariam a culpa. Em ambos os autores, Freud e Weber, a renúncia do prazer são as bases da formação da modernidade. Giddens $(2002,144)$, no entanto, apresenta uma ressalva: essa visão de uma modernidade fundada na repressão parece hoje incongruente com "a aparente permissividade moral da modernidade tardia"; de modo que, ao invés da culpa fundada nos ditames do que não pode ser feito, em uma modernidade tardia, temos a vergonha como processo central que orienta o projeto reflexivo do eu. Como essa vergonha se expressa? Segundo Han (2018b), pelo fracasso em fazer. Se o protestante trabalhava angustiado pelo medo da condenação, para o empresário de si mesmo a condenação é não ser 
capaz de dar conta de tudo que almeja, é não ser ativo e produtivo o bastante - é fracassar diante dos próprios anseios, que sente como individuais. Para o sujeito do desempenho, angustiado pelo fazer, a depressão é o seu inferno, que se sucede ao esgotamento e cansaço.

À conclusão semelhante chega Ehrenberg (2010) ao refletir sobre a mentalidade orientada para a performance, que impulsiona cada um ao governo de si, e, por isso, pela gestão individualizada de responsabilidades e consequências do agir, e o surgimento de novas psicopatologias. Uma cultura orientada para a performance não apresenta mais aqueles sintomas psicopatológicos neuróticos da época de Freud, mas um conjunto novo de psicopatologias depressivas e expressas em queixas relativas à impotência, à desesperança e à desvalorização. Esse novo quadro psicopatológico é resultado das demandas por performance e resultados, por mudança permanente e flexibilidade e, sobretudo, pelas pressões por resultados. A mitologia de autorrealização (Ehrenberg 2010, 174) transforma o individuo em empreendedor de si, e o resultado deve ser o sucesso, e o sucesso deve ser visto, deve ser aparente e transparente.

É nesse sentido que o fazer econômico, enquanto produção individualizada e vista como livre, é complementado pelo aparecer. O que Han (2017a) chama de sociedade da transparência se refere a um novo imperativo moral que se complementa ao imperativo de liberdade e de produção, que é de participar ativamente nas redes digitais, mostrar que se está agindo, esperar a recompensa por sua ação. Se age para mostrar, se faz para exibir, para assim ser gratificado, em uma espécie de condicionamento circular, encadeado, que é a forma acabada de um tipo de sociedade. Vivendo um panóptico digital, sendo transparentes e ativos, os sujeitos do desempenho não são mais supervisionados por ninguém, eles se observam entre si, se reforçam entre si, são vigias e presos simultaneamente.

Em seu ensaio sobre as grandes cidades, Simmel (2005) apontava como um dos grandes problemas da vida na metrópole moderna a contradição entre se viver sob excesso de estímulos e não se sentir, por isso, estimulado por nada. Sob o nome de comportamento blasé, Simmel dava destaque ao embotamento emocional que o excesso de possibilidades, estímulos visuais e a orientação constante para o agir causavam nos habitantes das metrópoles modernas. Han (2017b), ao pensar as consequências do imperativo do fazer, na multitarefa como regra do capitalismo informacional, no aparecer e estar em evidência como norma da sociabilidade nas redes sociais, chega em uma conclusão ainda mais radical: da sociedade disciplinar para a sociedade do desempenho, com a psicopolítica da autoexploração, vivemos na atenção profunda de tudo fazer, de buscar sempre o novo, e o resultado esperado disso é o tédio e o cansaço. Se o cidadão metropolitano do início do século 20 vivia entediado pelos excessos, o cidadão hiperestimulado do século 21 se vê não só entediado, mas cansado e deprimido (Han 2018a).

\section{Liberdade e mal-estar contemporâneo}

A civilização moderna possuía uma direção clara, embora contingente. Tratava-se de uma ordem pautada na valorização simbólica e das lutas em torno de valores relativos ao autocontrole e a racionalidade. Ser controlado, reprimir os impulsos, era fonte de valor social. O autocontrole, como repressão social internalizada, atuava como autopunição, como vergonha e culpa, inibindo a expressão emocional, a agressividade e a sexualidade. A civilização favoreceu a pacificação, que significa, para Elias (2011), a inibição da violência física nos espaços sociais, restando apenas a autorização para a violência simbólica das disputas sociais em torno de valores. Para Elias, ser civilizado era ser psicologizado, isto é, internalizar o outro como uma imagem complexa, repleta de motivos e conexões causais, e, também, ser racionalizado, agindo por meio de cálculos, previsões e expectativas. Mas Elias destaca, a civilização se mantém por meio de um modelo de sociedade e de suas disputas.

Em Considerações atuais sobre a guerra e a morte, Freud (2010a) traz uma reflexão que tem como desencadeadora a Primeira Guerra Mun- 
dial; são feitas indagações sobre os retrocessos civilizatórios que a experiência da guerra representa, sobre a desilusão provocada por tal conflito violento. Ali ele já refletia sobre as regras da vida civilizada, sobre a capacidade ordenadora dessas regras, mas já advertia: a civilização é algo muito vulnerável também, e a guerra é a amostra disso; a civilização é um esforço coletivo, e a paz dela decorrente precisa ser mantida e cultivada. $\mathrm{Na}$ guerra a civilização é suspensa, a brutalidade retorna, e tudo o que era reprimido se vê autorizado; é na guerra que vemos a importância da civilização e, também, sua vulnerabilidade. A guerra também mostra a virtude da civilização para conter os instintos e assegurar alguma paz. A repressão social, que se torna autorepressão ali the afigura como positiva, como contenção da violência. Ademais, e mais importante, ai fica claro que a civilização e a repressão são contingências de uma sociedade, podendo essas repressões serem suspensas em eventos particulares, com o decorrer da história. Elias (1997) também discute a suspensão da civilização e o colapso da repressão civilizatória durante a Segunda Guerra Mundial, e a partir dai reforça: nossas coações não são inatas, não são propriedades universais, são mantidas em um modelo de sociedade, alteradas quando esses modelos são alterados, de modo que o autocontrole e a autorepressão típicos da civilização, em um contexto de outro tipo, podem se alterar, seja em sua completa negação, seja em seu inverso. Se a civilização não é uma conquista permanente, tampouco o mal-estar é imutável.

Em sua reflexão sobre o mal-estar da pós-modernidade, Bauman (1998) retoma Freud (2011) e Elias (1993), para destacar que civilização é ganho de alguma coisa, mas perda de outras coisas. Limpeza e ordem foram, na modernidade, o ganho da civilização. O projeto de uma modernidade civilizada não tolerava a ambivalência, e a constância de uma sociedade nacional, ordenada, estratificada, científica, era a garantia de uma ordem produtiva, certamente repressiva, mas que poderia garantir a segurança. Hoje, isso se inverte, e busca-se viver na ambivalência, fazer de si um projeto inacabado, que não pode ser fechado em regras (Bauman
1999, 244-298). Um modelo societário é mantido e internalizado na medida em que é empreendido algum esforço em sua manutenção, e apenas em um conjunto de relações e figurações nos quais ele garante a troca e a disputa. Desse modo, em uma sociedade globalizada, com um capitalismo informacional, com as demandas sociais de ampliação de liberdades individuais, o imperativo civilizatório se transforma, e com isso temos um novo mal-estar que

[...] provém de uma espécie de liberdade de procura do prazer que tolera uma segurança individual pequena demais. [...] liberdade sem segurança não assegura mais firmemente uma provisão de felicidade do que segurança sem liberdade (Bauman 1998,10).

É típico que sociedades se vejam sob uma ótica favorável, e considerem seus valores como valores a serem defendidos como positivos, e afirmados como elementos constituintes de sua estima de grupo (Elias e Scotson 2000). É a na apresentação favorável da coerção da liberdade que uma sociedade psicopolítica convive com seu mal-estar. Simmel (2006), em um texto sobre as ideias de indivíduo e sociedade nos séculos 18 e 19, discute como liberdade é uma dessas ideias maleáveis, que mudam ao longo do tempo, mas que tende a ser identificada como algo de ideal em uma sociedade, com suas buscas e ambições. Se para no século 18 a liberdade representava a crítica dos privilégios da aristocracia e o indivíduo era um sujeito universal, típico da filosofia iluminista, no século 19 a liberdade se aproximava da igualdade, apenas sendo possivel fora do individualismo, e o individuo se apresentava como autonomizado e diferenciado pelo trabalho especializado. A relação entre indivíduo e liberdade nunca é estática, e os séculos 20 e 21 produziram uma nova relação.

Para Han (2018b) vivemos sob a égide de uma nova ideia de liberdade, e ela é fonte de legitimação de novas formas de submissão e coação. Para ele, a nova forma de submissão é consequência da libertação, e se consolida mediante um conjunto de ideias que negam qualquer submissão, apresentando-a como liberdade, ou 
como projetos livres, como construção individual de um eu sem coações externas. A contradição desse processo está na liberdade ter sido transformada na forma perfeita de coação, por meio de coações internas voltadas para o desempenho, a exposição, a produção (de si, das coisas, das vivências). Ou, dito de outra forma, "substitui-se o dever pelo poder, pois a liberdade do poder produz até mais coações do que o dever disciplinar, que expressa regras e interditos. O dever tem um limite, o poder não" (Han 2018b, 9-10).

A partir de Engels e Marx (1998) notamos que a ideologia, muitas vezes, nos aparece como um modo de justificação de um modelo societário ou como um modo de inversão das relações do poder, que ofusca as relações reais. Para Marcuse (1973) a ideologia da sociedade industrial era a da funcionalidade, da produtividade e da quantificação; o utilitarismo era sua crença fundamental de uma sociedade fundada em instrumentos técnicos neutros, vistos como objetivos e alheios à experiência humana, ela englobava a crença no progresso tecnológico em uma sociedade industrial disciplinada. Em uma sociedade do desempenho, Han (2017b) identifica que um aspecto dessa ideologia da sociedade industrial se mantém: a produção e o fazer como aspecto definidor da vida que vale a pena ser vivida. Zizek (1992), por sua vez, aproxima ideologia do inconsciente para nos trazer a dificil constatação de que por meio de belas palavras, de uma crença vista como positiva, muitas vezes se omite algo de terrivel e assustador, sua revelação como inconsciente ou como ideologia. Nesse sentido, a ideologia dominante em um novo capitalismo contemplaria não mais as limitações disciplinares de um capitalismo industrial, mas a liberdade levada até o limite de uma permissividade hedonista (Zizek 2011), mas nunca percebida como dominação. Ao pensar a ideologia de uma sociedade do desempenho, Han destaca, tal como Zizek (2011), que indivíduo e liberdade são algumas dessas palavras que hoje mobilizam ideologicamente e que, por isso, em seu sentido positivo trazem algo a ser ofuscado ou negado, a própria lógica de dominação ideológica. São nessas palavras, indivíduo e liberdade, que são depositadas as cargas da necessidade psicopolítica do fazer, que deixa de ser uma necessidade social e passa a ser encarada como uma necessidade individual. Não mais as repressões, mas as coações internalizadas como liberdade são a fonte de nossos mal-estares enquanto sofrimento coletivamente partilhado, mas apenas individualmente percebido.

A psicopolítica é uma política existencial, se relaciona com o problema da finitude do tempo e da existência, das possibilidades e das necessidades, da contingência de ser-no-mundo. A psicopolítica mobiliza a angústia de tudo ser e tudo fazer e coloca seu peso no individuo. Tal como na vivência da angústia em Kierkegaard (2007), que se trata de um sofrimento da liberdade, um medo sem foco e generalizado porque direcionado para o futuro, gerada pelas possibilidades limitadas de escolhas, o indivíduo produtivo e criador da contemporaneidade vive o problema da escolha, mas a angústia contemporânea é de outro caráter, não é a ansiedade de escolha diante de opções, mas a necessidade de deixar tudo em aberto, de tudo fazer, ou melhor, de ser aberto e abarcar a tudo. $\mathrm{O}$ angustiado descrito por Kierkegaard (2007) quer cessar a angústia e, por isso, se vê obrigado a uma escolha, mas o angustiado de uma sociedade neoliberal é aquele que precisa viver nessa angústia, que faz dela a normalidade, porque anseia sempre por fazer mais e não pode renunciar a opções. Por sua vez, se o ser-para-a-morte de Heidegger (2004) é aquele que enfrenta a finitude, sabe que o fim the é uma coação, e que diante do tempo que passa rumo à morte precisa decidir, o sujeito do desempenho não só não se abre para a morte, como evita qualquer escolha definitiva, quer abarcar o mundo e se exaure nessa busca. O mal-estar da sociedade contemporânea e de sua psicopolítica, com seus algozes que são vítimas de si mesmos, é a coação sob discurso de liberdade, é a autoexploração normalizada como prática cotidiana, a autoafirmação como norma de interação, é o cansaço da obrigação do fazer e agir, que se não for levada adiante, tal como na velha repressão, é sentida como vergonha ou culpa. 


\section{Referências}

Arendt, Hannah. 2007. A condição humana. $10^{a}$ ed. Rio de Janeiro: Forense Universitária.

Bauman, Zygmunt. 1998. O mal-estar da pós-modernidade. Rio de Janeiro: Zahar.

Bauman, Zygmunt. 1999. Modernidade e ambivalência. Rio de Janeiro: Zahar

Bauman Zygmunt. 2001. Modernidade líquida. Rio de Janeiro: Zahar.

Boltanski, Luc e Ėve Chiapello. 2009. O novo espirito do capitalismo. São Paulo: Martins Fontes.

Dalgalarrondo, Paulo. 2008. Psicopatologia e semiologia dos transtornos mentais. $2^{\mathrm{a}}$ ed. Porto Alegre: Artmed.

Ehrenberg, Alain. 2004. Depressão, doença da autonomia? Entrevista de Alain Ehrenberg a Michel Botbol. Ágora 7 (1): 143-153. https://doi.org/10.1590/S151614982004000100009 .

Ehrenberg, Alain. 2010. O culto da performance: da aventura empreendedora à depressão nervosa. Aparecida: Idéias \& Letras.

Elias, Norbert. 1993. Sugestões para uma teoria de processos civilizadores. In O processo civilizador. Formação do estado e civilização, 193-274. Vol. 2. Rio de Janeiro: Zahar.

Elias, Norbert. 1997. Colapso da civilização. In Os alemães. A luta pelo poder e a evolução do habitus, 267-300. Rio de Janeiro: Zahar

Elias, Norbert. 1998. Sobre o tempo. Rio de Janeiro: Zahar

Elias, Norbert e John L. Scotson. 2000. Os estabelecidos e os outsiders: sociologia das relações de poder a partir de uma pequena comunidade. Rio de Janeiro: Zahar.

Elias, Norbert. 2001a. Particularidades da figuração aristocrática de corte. In A sociedade de corte, 85-96. Rio de Janeiro: Zahar

Elias, Norbert. 2001b. A solidão dos morimbundos. Seguido de envelhecer e morrer. Rio de Janeiro: Zahar.

Elias, Norbert. 2011. Da sociogênese dos conceitos de civilização e cultura. In O processo civilizador. Uma história dos costumes, 21-61. Vol. 1. $2^{\mathrm{a}}$ ed. Rio de Janeiro: Zahar.

Engels, Fredrich e Karl Marx. 1998. A ideologia alemã. São Paulo: Martins Fontes.

Freud, Sigmund. 2010a. Considerações atuais sobre a guerra e a morte. In Introdução ao narcisismo, ensaios de metapsicologia e outros textos [1914-1916], 156-170. Vol. 12. São Paulo: Companhia das Letras.

Freud, Sigmund. 2010b. A transitoriedade. In Introdução ao narcisismo, ensaios de metapsicologia e outros textos [19141916], 184-189. Vol. 12. São Paulo: Companhia das Letras.

Freud, Sigmund. 2011. O mal-estar da civilização. São Paulo: Companhia das Letras.
Freud, Sigmund. 2012. Totem e tabu. In Totem e tabu, contribuição à história do movimento psicanálitico e outros textos [1912-1914]. Vol. 11. São Paulo: Companhia das Letras.

Foucault, Michel. 1979. Soberania e disciplina. In Microfísica do poder, 179-192. 25 ed. São Paulo: Graal.

Foucault, Michel. 1999. Em defesa da sociedade. São Paulo: Martins Fontes.

Foucault, Michel. 2008. Nascimento da biopolitica: curso dado no Collège de France (1978-1979). São Paulo Martins Fontes.

Foucault, Michel. 2014. Vigiar e punir. $42^{\mathrm{a}}$ ed. Petrópolis Vozes.

Giddens, Anthony. 2002. Modernidade e identidade. Rio de Janeiro: Zahar.

Han, Byung-Chul. 2017a. Sociedade da transparência Petrópolis: Vozes.

Han, Byung-Chul. 2017b. Sociedade do cansaço. $2^{\mathrm{a}}$ ed. Petrópolis: Vozes.

Han, Byung-Chul. 2018a. No enxame: perspectivas do digital. Petrópolis: Vozes.

Han, Byung-Chul. 2018b. Psicopolitica: o neoliberalismo e as novas técnicas de poder. Belo Horizonte: Âyiné.

Illouz, Eva. 2011. O Amor nos tempos do capitalismo. Rio de Janeiro: Zahar.

Heidegger, Martin. 2004. Ser e tempo. Vol. 1. $13^{\mathrm{a}}$ ed. Petrópolis: Vozes

Kierkegaard, Soren Aabye. 2007. O conceito de angústia. São Paulo: Hemus.

Levi-strauss, Claude. 1982. As estruturas elementares do parentesco. $5^{\text {a }}$ ed. Petrópolis: Vozes.

Marcuse, Herbert. 1973. Ideologia da sociedade industrial. o homem unidimensional. $4^{\mathrm{a}}$ ed. Rio de Janeiro: Zahar.

Marx, Karl. 2004. Trabalho estranhado e propriedade privada. In Manuscritos econômico-filosóficos, 79-90. São Paulo: Boitempo.

Mead, George Herbert. 2010. Mente, self e sociedade Aparecida: Idéias \& Letras.

Melossi, Dario e Massimo Pavarini. 2006. Cárcere e fábrica: as origens do sistema penitenciário (séculos $X V I-X I X)$. Rio de Janeiro: Revan.

Pierucci, Antônio Flávio. 1998. Secularização em Max Weber: da contemporânea serventia de voltarmos a acessar aquele velho sentido. Revista Brasileira de Ciências Sociais 13 (37): 43-73. https://doi.org/10.1590/ S0102-69091998000200003.

Rosa, Hartmut. 2019. Aceleração: a transformação das estruturas temporais na modernidade. São Paulo: Unesp.

Simmel, Georg. 2005. As grandes cidades e a vida do espírito. Mana. 11 (2): 577-591. https://doi.org/10.1590/ S0104-93132005000200010. 
Simmel, Georg. 2006. Indivíduo e sociedade nas concepções de vida dos séculos XVIII e XIX. In Questões fundamentais de Sociologia, 83-118. Rio de Janeiro: Zahar.

Weber, Max. 2006. A ética protestante e o espirito do capitalismo. São Paulo: Cia. das Letras.

Zizek, Slavoj. 1992. Eles não sabem o que fazem: o sublime objeto da ideologia. Rio de Janeiro: Zahar.

Zizek, Slavoj. 2011. Em defesa das causas perdidas. São Paulo: Boitempo.

\section{Alan Delazeri Mocellim}

Doutor em Sociologia pela Universidade de São PauLo, (USP), São Paulo, SP, Brasil; professor adjunto do Departamento de Sociologia da Universidade Federal da Bahia, (Ufba), Salvador, BA, Brasil e do Programa de Pós-Graduação em Ciências Sociais da mesma instituição. 